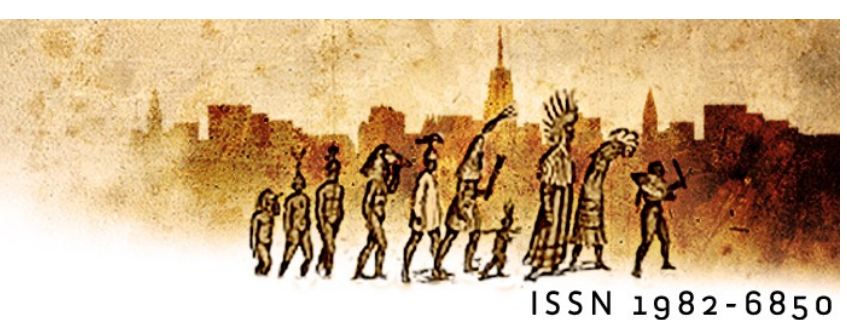

\title{
A difusão do pensamento bakhtiniano no Ocidente: uma leitura dos contextos de recepção no Brasil $^{1}$
}

\author{
Benedita França Sipriano' (UECE) \\ João Batista Costa Gonçalvesii (UECE)
}

\begin{abstract}
Resumo: A consolidação do pensamento do teórico russo Mikhail Bakhtin (1895-1975) como influenciador de diversas áreas das ciências humanas, em especial os estudos da linguagem, foi construída historicamente, a partir de valores e confrontos em determinadas conjunturas socioideológicas. Este artigo objetiva discutir sobre o processo de difusão do pensamento bakhtiniano no Ocidente, sobretudo nos diferentes contextos de recepção dessa abordagem no Brasil, abordando, em especial, a questão das traduções da obra bakhtiniana no país. O trabalho discute, também, a problemática dos "textos disputados" e o debate sobre a configuração do chamado Círculo de Bakhtin, com ênfase para uma reflexão sobre o lugar ocupado pelos estudiosos russos $\mathrm{V}$. N. Volóchinov e P. N. Medviédev na constituição desse arcabouço teórico-metodológico. Por fim, pode-se destacar que a chamada Análise Dialógica do Discurso não é uma abordagem fechada e não se configura como um campo delimitado de análise do discurso, mas é fruto do trabalho de estudiosos brasileiros que vêm desenvolvendo pesquisas cujo fico condutor é a concepção sócio-histórico-ideológica de linguagem empreendida pelo Círculo de Bakhtin.
\end{abstract}

Palavras-chave: Círculo de Bakhtin. Contextos de recepção. Produção do conhecimento acadêmico.

\begin{abstract}
The consolidation of the thought of the Russian theorist Mikhail Bakhtin (1895-1975) as an influencer of several fields of human sciences, mainly language studies, was also historically constructed from values and confrontations in certain socio-historical contexts. This article aims to discuss about the process of diffusion of the Bakhtinian thought in the West, in different contexts of reception of this approach in Brazil, discussing, in particular, the issue regarding the translations of Bakhtin's work in the country. The work also focuses on the question of the "disputed works" and on the debate about the configuration of the Bakhtin Circle,
\end{abstract}

\footnotetext{
${ }^{1}$ Este trabalho apresenta parte da discussão desenvolvida por Sipriano, em pesquisa de doutorado, no Programa de Pós-Graduação em Linguística Aplicada da Universidade Estadual do Ceará (PosLA/UECE).
} 
with emphasis on a reflection about the place held by the Russian scholars V. N. Volóchinov and P. N. Medviédev in the constitution of this theoretical and methodological framework. Finally, it is possible to highlight that the so-called Dialogic Discourse Analysis is not a closed approach and does not constitute a defined field of discourse analysis. It is rather the result of the work of Brazilian scholars that have developed researches whose guiding principle is the ideological, historical and social conception of language undertaken by the Bakhtin Circle.

Keywords: Bakhtin Circle. Contexts of reception. Production of academic knowledge.

\section{Introdução}

É incontestável a influência e relevância do pensamento do teórico russo Mikhail Bakhtin (1895-1975) nas mais diversas áreas do conhecimento, como filosofia, história, ciências sociais e, sobretudo, linguística e literatura. Nos estudos linguísticos, a recepção das obras do chamado Círculo de Bakhtin, na Rússia e no mundo ocidental - em especial, a partir da segunda metade do século XX - contribuiu para uma ruptura de paradigmas, trazendo à cena o debate acerca do caráter sócio-histórico-ideológico da linguagem. Contudo, como pontua Brait (2009), "compreender o que se denomina pensamento bakhtiniano significa percorrer um caminho que envolve não apenas o indivíduo Bakhtin, mas um conjunto de intelectuais, cientistas e artistas que, especialmente nas décadas de 1920 e 1930, dialogaram em diferentes espaços políticos e sociais" (BRAIT, 2009, p. 15). Assim, leituras que caracterizam Bakhtin como um pensador totalmente original, um verdadeiro "gênio monumental", precursor de diversas escolas de pensamento, há muito tempo vêm sendo questionadas por uma série de pesquisas que propõem uma compreensão mais ponderada acerca do legado desse teórico.

Nessa perspectiva, a trajetória que envolve o processo de "redescoberta" do pensamento bakhtiniano, na Rússia, a partir dos anos 1960, e sua posterior recepção no mundo ocidental, sobretudo a partir dos anos 1970, é intricada e envolve percalços (que não podem ser desconsiderados), tais como: a) a polêmica em torno da autoria dos textos "disputados" e, ainda, a pertinência da designação "Círculo de Bakhtin"; b) a falta de ordem cronológica ou unidade temática que caracterizou a publicação e a tradução dos textos de Bakhtin e seus contemporâneos (tanto na Rússia, quanto no ocidente); e c) os desafios da tradução de textos produzidos em contextos histórico-culturais muito díspares em relação ao contexto de recepção do pensamento bakhtiniano no Ocidente. 
Dessa forma, este artigo se propõe a desenvolver uma discussão acerca da difusão dessa perspectiva teórica no mundo acadêmico, em especial, entre nós, pesquisadores brasileiros, e, por fim, uma reflexão sobre a pertinência, relevância e atualidade dessa abordagem, para que esta seja uma lente a partir da qual podemos analisar uma diversidade de questões que emergem nos estudos linguísticos contemporâneos.

\section{0 "Círculo de Bakhtin, Volóchinov, Medviédev"}

Neste trabalho, utilizamos, indistintamente, as expressões "Círculo de Bakhtin", "Círculo" ou, ainda, "Círculo Bakhtin, Medviédev, Volóchinov", para nos referirmos a esse "coletivo de pensadores", que, sem prejuízo para a autonomia intelectual de cada um, e a despeito de significativas diferenças de perspectiva epistemológica, protagonizou um profícuo diálogo que pode ser reconstituído por nós, pesquisadores, a partir de um olhar sobre a recorrência de temas e categorias presentes na produção teórica desses autores.

Além disso, desde os anos 1990, vem ocorrendo uma verdadeira "reabilitação" dos nomes dos pesquisadores russos V.N. Volóchinov e M. Medviédev, que não podem ser considerados meros alunos ou seguidores de Bakhtin, pois foram intelectuais com uma renomada e produtiva carreira profissional e acadêmica, a despeito da morte prematura de ambos, na Rússia, no final dos anos 1930. Daí, reiteramos, a utilização, neste artigo - assim como utilizado por diversos outros estudiosos - da designação "Círculo Bakhtin, Medviédev, Volóchinov", o que atesta a relevância e o lugar ocupado por esses teóricos no que hoje chamamos "pensamento bakhtiniano". Contudo, como as formas de nomear assinalam determinados posicionamentos, muitos estudiosos questionam a pertinência da designação "Círculo de Bakhtin", o que gera um debate que sintetizamos a seguir.

O psicolinguista A. A. Leontev, em um artigo publicado em Leningrado, em 1967, menciona a existência de um "círculo de Bakhtin", expressão até então desconhecida entre os comentadores desse teórico russo. Em 1969, Leontev cita passagens de Marxismo e Filosofia da Linguagem (MFL) para indicar as posições do referido "círculo" ${ }^{2}$. O termo logo se popularizou e passou a ser difundido entre os estudiosos do pensamento bakhtiniano para, inicialmente, metaforizar a liderança intelectual de Bakhtin sobre um grupo de pensadores com quem convivera na Rússia, entre os anos de 1919 a 1929, nas cidades de Nevel, Vitebsk

\footnotetext{
${ }^{2}$ Cf. Clark e Holquist (2004, p. 172); Sériot (2015, p. 29)
} 
e São Petersburgo (Leningrado)3, entre eles Maria V. Iudina (1899-1970), Matvei Isaevich Kagan (1889-1937), Ivan I. Kanaev (1893-1984), Pavel Nikolaevich Medviédev (1891-1938), Lev Vasilievich Pumpianskii (1891-1940), Konstantin K. Vaginov (1899-1934) e Valentin Nikolaevich Volóchinov (1895-1936).

Conforme Brandist (2002) o chamado Círculo de Bakhtin, em alguns aspectos, herdou a tradição dos "círculos de discussão" (krug) que tinham sido a principal forma de vida intelectual na Rússia desde a década de 1830. Esse autor ressalta que o atraso econômico e político da Rússia czarista, entre outros aspectos, criou uma intelligentsia articulada fora de instituições formais. Diante da censura czarista, era frequente a formação de círculos secretos de discussão em que seus ideais poderiam ser expressos. Ainda segundo Brandist, esses grupos se tornaram a base dos partidos políticos revolucionários que começaram a emergir no final século XIX. Já no período pós-revolução de 1917 e pósGuerra Civil (1917-1922), eram possíveis formas mais abertas de vida intelectual; para aqueles, é claro, que não fossem hostis aos direcionamentos dos grupos políticos dominantes: é nessas circunstâncias que o Círculo Bakhtin, Medviédev, Volóchinov foi se constituindo.

Brandist (2012) relata que, quando realizou sua pesquisa arquival na Rússia, no início dos anos 1990, não tinha ainda consciência de como a noção de haver um Círculo de "Bakhtin", era, na verdade, bastante problemática, até porque os membros do chamado Círculo pertenciam a variados grupos intelectuais. Assim, esse autor adverte:

O que hoje, na ausência de expressão melhor, chamamos de Círculo de Bakhtin, é, na verdade, apenas um ponto no qual diferentes pensadores se intersectavam e não é de modo algum certo que, para qualquer dos participantes, esse fosse o mais importante dos agrupamentos a que eles pertenciam (BRANDIST, 2012, p. 8).

Assim, é importante termos sempre em vista que essa designação foi construída posteriormente pelos estudiosos do pensamento bakhtiniano, ou seja, não houve, propriamente, um grupo de pesquisadores russos que se autodenominava "Círculo de Bakhtin". Além disso, os membros do chamado "Círculo", na verdade, participavam de diversos outros "círculos".

\footnotetext{
${ }^{3}$ Em função de uma série de questões políticas e ideológicas, ao longo do século $X X$, a cidade de São Petersburgo, Rússia, recebeu diferentes designações: de 1914 a 1924, teve o nome alterado para Petrogrado; no período de 1924 a 1991, foi renomeada como Leningrado; e, em 1991, voltou à sua designação original: São Petersburgo.
} 
Nessa perspectiva, autores como Sériot (2015) negam peremptoriamente a existência de um "Círculo de Bakhtin" e questionam a adequação do termo, que centralizaria a ideia de "círculo" na figura de Bakhtin e desconsideraria a relevância de outros intelectuais que "não tiveram a honra de ser traduzidos". Sériot (2015, p. 30) destaca, ainda que, "se, de fato, houve um círculo, não é de forma alguma necessário chamá-lo 'de Bakhtin"'. Assim, esse autor defende que "a expressão Círculo de Bakhtin é uma invenção tardia e apócrifa. [...] Ela contribuiu para a edificação do mito, do Grande Relato em que a encantação e a íntima convicção substituem a prova e o argumento (SÉRIOT, 2015, p. 28).

Certamente, a atuação de estudiosos como M. Medviédev e V. N. Volóchinov - no percurso de configuração daquele coletivo que viria a ser designado como "Círculo de Bakhtin" - não foi secundária. Após a Revolução de 1917 e com o início da guerra civil na Rússia, diversos intelectuais e artistas se refugiaram na cidade de Nevel, a cerca de $800 \mathrm{~km}$ de Moscou. Em busca de melhores condições de subsistência, M. Bakhtin e V. N. Volóchinov se conheceram nesta cidade, onde havia um intensa vida cultural, mesmo naqueles sombrios tempos de guerra. Eles tinham vindo da então Petrogrado, cidade palco dos horrores bélicos, e, em Nevel, participaram ativamente da vida intelectual, tendo contato com pensadores como Lev Pumpianskii, Maria Iudina, Mikhail Tubianski, Ana Sergueiévna e Matvei Kagan. Em 1919 e 1920, muitos desses intelectuais migraram para a vanguardista Vitebsk, onde puderam contar com o apoio do crítico literário e historiador da literatura, reitor da recém-inaugurada Universidade Proletária, P. N. Medviédev (que também, era articulador de diversas atividades artístico-culturais, inclusive era editor de uma revista cultural, na qual V.N.Volóchinov publicou textos). Brandist (2002) destaca, sobre este período, que essa migração para Vitebsk assinala que o "círculo" não se limitou à filosofia acadêmica, mas tornou-se estreitamente envolvido nas atividades culturais da época, naquela cidade que era palco de um verdadeiro "renascimento cultural", conforme também discutido por Medviédev; Medviédeva; Shepherd (2016). Nesse contexto, a posição política estabelecida por Medviédvev, que, por um tempo, exerceu, até mesmo, uma função equivalente a prefeito de Vitebsk ${ }^{4}$, possibilitou que ele contribuísse com uma série de

\footnotetext{
${ }^{4}$ Cf. Sériot (2015, p. 34) e Brandist (2002, p.6).
} 
atividades artísticas e acadêmicas, entretanto, mais tarde, nos anos 1930, o tornará um alvo dos expurgos de J. Stalin 5 .

Em 1922, Medviédev e Volóchinov voltaram a viver em Petrogrado-Leningrado, para onde também segue, em 1924, M. Bakhtin. Conforme Brandist (2002), a maior parte do trabalho significativo do grupo foi produzida após a mudança para Leningrado, onde novos membros se juntaram ao Círculo, como o biólogo e historiador da ciência Ivan I. Kanaev e o especialista em filosofia e religião oriental, Mikhail I. Tubianski. Nesse período, em Petrogrado-Leningrado, emergem e aprofundam-se as investigações nos campos da filosofia da linguagem, psicologia, filosofia e poética.

V. N. Volóchinov, de 1922 a 1924, graduou-se em Etnologia e linguística, na Universidade de Petrogrado ${ }^{6}$, onde se iniciou na problemática da psicologia, da linguística e do marxismo. Em 1925, ingressa no Instituto da História Comparada das Literaturas e Línguas do Ocidente e Oriente (ILIAZV), como monitor de cursos e pesquisador colaborador. Em 1926, torna-se doutorando dessa instituição, com um trabalho inserido na Subseção de Metodologia da Literatura, sob orientação do marxista literário crítico V.A. Desnitskii e assessoria do linguista e estudioso da temática do "diálogo" Lev lakubinski. P. $\mathrm{N}$. Medviédev era um pesquisador externo de primeiro grau do ILIAZV, onde organizou e liderou a Seção de Poética Sociológica, na qual estava inserido o trabalho de Volóchinov.

Assim, pesquisas nos arquivos de ILIAZV (onde P. Medviédev e V. Volóchinov trabalharam entre 1925 e 1932), que vêm sendo divulgadas desde os anos 1990, são de fundamental importância para a compreensão do trabalho do chamado Círculo de Bakhtin em seu contexto histórico ${ }^{7}$. Medviédev, Medviédva e Shepherd (2016) defendem que houve um diálogo entre as pesquisas do ILIAZV, uma "concepção compartilhada", com uma

\footnotetext{
${ }^{5}$ O perfil biográfico e acadêmico de Pável Nicoláievitch Medviédev pode ser conferido na nota biográfica (constante na edição brasileira de $O$ Método Formal nos Estudos Literários) escrita por seu filho, o filólogo, historiador de cultura e crítico russo, lúri Pávlovitch Medviédev (MEDVIÉDEV, 2012)).

${ }^{6}$ Em 1917, Volóchinov havia interrompido a graduação na Faculdade de Direito de S. Petersburgo, por problemas financeiros e familiares. Informações sobre o perfil biográfico e acadêmico de V. N. Volóchinov são discutidas em autores como Grillo e Américo (2017), Sériot (2015) e Brandist (2002, 2006).

7 Em artigo sobre a atuação acadêmica de V. N. Volóchinov no ILIAZV, de 1925 a 1932, Grillo e Américo (2017) constatam que escritos de $O$ Método Formal nos Estudos Literários e Marxismo e Filosofia da Linguagem aparecem nos relatórios de doutorado desse acadêmico ao Instituto. Entre os trabalhos mencionados por Volóchinov, consta a produção dos artigos: "Do outro lado do social", que se transformou no livro Freudismo: um esboço crítico, "A palavra na vida e a palavra na poesia", "As mais novas correntes do pensamento linguístico no Ocidente" (que, em nota de rodapé, informa tratar-se de um resumo expandido de três capítulos do livro Marxismo e Filosofia da Linguagem), "O problema da transmissão do discurso alheio" (ensaio de pesquisa sociolinguística).
} 
diversidade de temáticas, sem que isso, contundo, pudesse comprometer a autonomia intelectual de Bakhtin, Volóchinov e Medviédev.

Sobre esse ambiente colaborativo da Leningrado dos anos 1920, Grillo e Américo (2017) destacam - a partir da análise dos relatórios de Volóchinov no ILIAZV, de 1925 a 1932 - a presença, nesses arquivos, de temas que posteriormente foram trabalhados por Medviédev e Bakhtin, "podendo indicar a estreita colaboração acadêmica dos autores entre 1925 e 1929, quando os três se encontravam em Leningrado" (GRILLO; AMÉRICO, 2017, p. 278).

Bakhtin foi preso em 1929, presumivelmente por sua conexão com o grupo religiosofilosófico Voskresenie (Resurreição) e, em virtude disso, acabou sendo condenado a alguns anos de exílio em Kustanai, Cazaquistão. Com a saúde abalada, Bakhtin chega a essa cidade no ano de 1930, onde passa a viver, proibido de lecionar em escolas formais.

Já nos anos 1950, época em que esboça o ensaio "Os gêneros do discurso", Bakhtin torna-se professor de literatura russa e estrangeira na Universidade de Mordóvia (antigo Instituto Pedagógico). A "redescoberta" do pensamento bakhtiniano ocorreu nesse período, por iniciativa de estudantes de pós-graduação do Instituto Gorki de Literatura Mundial, da Academia de Ciências de Moscou, que fizeram o resgate do autor do livro Problemas da obra de Dostoiévski, publicado, em $1929^{8}$. Por incentivo desses acadêmicos, Bakhtin preparou uma nova edição da obra sobre Dostoiévski - a qual foi publicada, em Moscou, em 1963, com acréscimos e reformulações ao texto original, inclusive no título: Problemas da Poética de Dostoiévski - e do estudo sobre François Rabelais, que foi publicado, em 1965, sob o título A cultura popular na Idade Média e no Renascimento: o contexto de Francois Rabelais.

Na época de sua "redescoberta", quando o pensamento bakhtiniano foi retirado de anos de silêncio, esse teórico trabalhava discretamente, na escola de professores na província de Saransk, elevada à Universidade Estadual de Mordóvia, em 1957. O septuagenário Mikhail Bakhtin, nascido em Orel, em 1895, testemunha o renovado interesse da academia por sua produção teórica e vê seu nome tornar-se aclamado na vida intelectual russa. Até o ano do falecimento desse teórico, em 1975, em Moscou, foram publicados apenas os seus livros sobre Dostoiévski e sobre Rabelais. Esses discípulos que o

\footnotetext{
8 Entre esses estudantes, estavam Vadim Kojinov e Serguei G. Bocharov, os quais se tornaram os gerenciadores editoriais da produção intelectual de M. Bakhtin, seus testamenteiros literários.
}

Eutomia, Recife, 21(1): 120-143, Jul. 2018 
tiraram do ostracismo passaram a ter o controle sobre os arquivos do autor e organizaram várias publicações a partir dessas fontes, em grande parte, composta de esboços, anotações e manuscritos inacabados. A republicação e o lançamento da obra de Bakhtin, que teve início na Rússia, em 1963, estendeu-se até ao anos 1980 e não obedeceu uma ordem cronológica: um dos primeiros textos de Bakhtin, escrito entre 1920 e 1924, Para uma filosofia ato, teve a primeira edição em 1986. Entre 1997 e 2012, na Rússia, foram publicados os seis volumes da obra completa e comentada de M. Bakhtin, com organização dos herdeiros do espólio bibliográfico desse autor, Serguei Bocharov e Vadim Kojinov.

No ano de sua morte, 1975, foi publicada, na Rússia, a coletânea de manuscritos organizada pelo autor, Problemas de literatura e de estética: estudos de vários anos, que reúne textos escritos entre 1924 e 1941, além de um ensaio de $1973^{9}$. Em 1979, foi publicada a coletânea Estética da Criação Verbal. Organizada pelos arquivistas de Bakhtin, S.G. Bocharov e A. Avenritsev, possui textos publicados desde o início dos anos 1920, até ao anos 1970. Reunindo manuscritos inéditos e republicações, a coletânea traz o famoso texto "Gêneros do discurso"10.

\section{Sobre a difusão do pensamento bakhtiniano no Ocidente}

O fértil debate acadêmico acerca da influência e importância do pensamento de Mikhail Bakhtin nos estudos das ciências humanas e sociais apresenta, em sua trajetória, posicionamentos bastante antagônicos, como a "mitologia" e "hagiografia" em torno da figura do "gênio russo", empreendida e difundida a partir de trabalhos como a conceituada biografia Mikhail Bakhtin, escrita, nos anos 1980, pelos eslavistas norte-americanos Katerina Clark e Michael Holquist (2004 [1984]); e críticas sobre os processos de construção e "celebração" do "mito" Bakhtin, como a desenvolvida no audacioso trabalho dos pesquisadores franceses Jean Paul Bronckart e Cristian Bota ${ }^{11}$, publicado na França, em

\footnotetext{
${ }^{9}$ Esta obra foi traduzida no Brasil, em 1988, com o título Questões de Literatura e de Estética: a teoria do romance.

${ }^{10}$ Segundos os organizadores da coletânea, o texto "Os gêneros do discurso" trata-se de um esboço prévio de um livro sobre que Bakhtin pretendia escrever sobre essa temática Cf. (BAKHTIN, 2011, p.447).

${ }^{11}$ Jean-Paul Bronckart e Cristian Bota são pesquisadores da Universidade de Genebra, da Unidade de Didática de Línguas da Faculdade de Psicologia e Ciências da Educação. J. P. Bronckart é expoente do interacionismo sociodiscursivo, abordagem que tem relevante repercussão em diversas pesquisas em Linguística Aplicada no Brasil. Cf. edição especial sobre essa abordagem na Revista Veredas, V. 21, n. 3, 2017. Disponível em: <http://www.ufjf.br/revistaveredas/edicoes/2017-2/especial> Acesso em 12.jan.2018.
} 
$2011^{12}$, sob o título Bakhtine démasqué: histoire d'un menteur, d'une escroquerie et d'un délire collectif.

Essa polêmica obra dos estudiosos franceses - escrita em um tom e estilo que fogem aos padrões da linguagem acadêmica - tem o mérito de suscitar uma reflexão acerca de questões como os processos de produção de "paradigmas" no campo científico e sobre a importância de uma postura crítica e reflexiva por parte dos pesquisadores, para que não apenas reproduzam "verdades consagradas" e validadas pelo establishment acadêmico. Com foco no problema dos "textos disputados"13, esses autores têm o objetivo "desmascarar" Bakhtin (e muitos de seus promotores), por meio da análise de elementos da história do "bakhtinismo" (celebração e apogeu de Bakhtin e de sua obra), desenvolvido, sobretudo, a partir da recepção do pensamento bakhtiniano na Europa, nos Estados Unidos e na América Latina. O livro, por meio de uma análise da produção de comentadores da teoria bakhtiniana e de uma leitura comparativa entre textos de M. Bakhtin, V. N. Volóchinov e P. N. Medviédev, defende a autoria dos signatários das obras disputadas e questiona muitas das "certezas" sobre a figura intelectual de Bakhtin, difundidas e reproduzidas por seus comentadores, desde os anos 1970.

\footnotetext{
${ }^{12}$ A primeira tradução dessa obra foi a publicada no Brasil, em 2012, o que ilustra a popularidade do pensamento bakhtiniano entre o público-leitor brasileiro. Ver: Bakhtin Desmascarado: história de um mentiroso, de uma fraude, de um delírio coletivo (BRONCKART; BOTA, 2012). Em 2013, o livro foi traduzido na Espanha. A publicação deste trabalho suscitou diversas resenhas e um profícuo debate. No âmbito dessa discussão, no Brasil, a Bakhtiniana: Revista de Estudos do Discurso publicou uma edição especial sobre a temática em 2014. Disponível em: https://revistas.pucsp.br/index.php/bakhtiniana/issue/view/1255/showToc>. Acesso em 19 jan. 2018.

${ }^{13}$ Nos anos 1970, teve início a controversa questão da autoria dos "textos disputados", quando o linguista e semioticista russo $\mathrm{V}$. Ivanov afirmou, em nota de rodapé de um artigo publicado em uma série de semiótica, em Tartu, capital da Estônia, que textos cujos signatários eram P. N. Medviédev e V.N. Volóchinov, na verdade, seriam de autoria de M. Bakhtin. Ivanov, entretanto, não apresentava provas ou maiores esclarecimentos, apenas citava a existência de testemunhas, sem nomeá-las. Esse texto é o marco inicial da polêmica em torno da paternidade dos livros Freudismo (1927, assinado por Volóchinov), O Método Formal nos Estudos Literários (1928, assinado por Medviédev) e Marxismo e Filosofia da Linguagem (1929, assinado por V. Volóchinov), além de artigos assinados por $\mathrm{V}$. Volóchinov. A partir da declaração de $\mathrm{V}$. Ivanov, mesmo sem comprovação indiscutível, tornou-se lugar-comum, em sucessivas edições desses textos, em diferentes línguas, a atribuição da autoria de muitos desses trabalhos exclusivamente a M. Bakhtin. Também há edições em que aparece o artifício da utilização do nome dos dois autores: Bakhtin/Volóchinov ou Bakhtin/Medviédev. Pode-se destacar que, atualmente, a tese da onipaternidade dessas obras a Bakhtin vem perdendo cada vez mais força, principalmente em relação aos trabalhos de V. N. Volóchinov. Deve-se ressaltar, entretanto, que a atribuição da autoria das obras "contestadas" a Bakhtin ainda possui significativa adesão na Rússia, conforme destacado por Grillo (2012). No entanto, vale destacar que aspectos como política acadêmica e mercado editorial possuem grande peso nesse debate, que vem sendo cada vez mais heteroglóssico, graças ao empenho e posicionamento reflexivo de diversos pesquisadores da teoria bakhtiniana. Cf. Sériot (2015) e Morson e Emerson (2008).
} 
Contudo, o tom virulento e sarcástico desse "desmascaramento" e a construção da imagem de M. Bakhtin e seus promotores como personagens "mentirosos", "desonestos" e "ambiciosos" culmina em uma visão "escatológica" e "apocalíptica", que desconsidera qualquer relevância do papel de Bakhtin no campo da produção do conhecimento acadêmico. Além de negarem, definitivamente, a "onipaternidade" de Bakhtin em relação aos famosos "textos contestados", Bronckart e Bota (2012) defendem, inclusive, que há indícios de que esse pensador russo não é nem mesmo autor de outras obras cuja autoria Ihe é atribuída (e não havia sido questionada), entre elas Problemas da Poética de Dostoiévski (1929). Em contraponto à visão de Bakhtin como um "santo", um "gênio", a visão desse pensador como um "charlatão", um mero "plagiador".

O questionamento acerca da mitologia e da construção do "cânone Bakhtin" é relevante, pois favorece a ruptura com uma visão idealizada desse intelectual e o debate acerca dos limites e contribuições do legado do pensamento de M. Bakhtin. Entretanto, conforme ressalta Brandist (2012, p. 9), "desmistificar não é o mesmo que desmascarar". Esse processo de desmistificação da figura de Bakhtin, que já vinha sendo empreendido como já destacamos - em especial a partir dos anos 1990, por uma série de pesquisadores que fazem uma leitura mais ponderada sobre o legado bakhtiniano, fez emergir - no lugar de uma "figura mítica", "extremamente original" - os nomes de diversos pensadores que produziram ativamente, naquele contexto efervescente da Rússia, nas primeiras décadas do século XX. "O que vemos é que um grupo de pensadores muito mais interessante estava surgindo, encravados nas condições de seu tempo e época, e não figuras heroicas e excepcionais" (BRANDIST, 2012, p. 9).

Dessa forma, ao contrário de uma visão "apocalíptica" sobre o que hoje podemos chamar de "pensamento bakhtiniano", temos o posicionamento de diversos estudiosos que desenvolvem uma visão mais reflexiva e ponderada sobre as contribuições da produção teórica de M. Bakhtin e seus contemporâneos (em especial para os estudos da linguagem), em discussões de autores como Medviédev; Medviédva (2014); Medviédev; Medviédva; Shepherd (2016); Sériot (2015), Brandist (2012, 2002), Morson e Emerson (2008) e Emerson (2003). Além, é claro, do papel fundamental de pesquisadores brasileiros que vêm desenvolvendo trabalhos sérios e fundamentados, cujo fio condutor é a concepção dialógica e sócio-histórico-ideológica da linguagem, como Brait (2006, 2008, 2009, 2010); Faraco (2009, 2014), Grillo (2012, 2014, 2017) e Paula e Stafuzza (2010, 2011, 2013), entre tantos 
outros estudiosos com relevantes contribuições. Essa leitura brasileira do pensamento bakhtiniano é designada por diversos autores como Análise Dialógica do Discurso. Brait (2012, p.12) ressalta que, atualmente, diversas abordagens, como a Linguística Aplicada, a Teoria Literária e os estudos da comunicação, "remetem e/ou referem-se à concepção bakhtiniana de linguagem, dela se utilizando com diferentes objetivos e com importantes consequências para seus horizontes teóricos e metodológicos".

Com relação à emergência do pensamento bakhtiniano no ambiente intelectual russo pós-Stálin, nos anos 1960, é importante destacar que essa abordagem foi inserida na arena de confrontos entre as abordagens estruturalista/formalista (físicos) e humanista marxista-leninista (líricos), conforme discutido por Morson e Emerson (2008). Esses autores ressaltam que, apesar de Bakhtin nunca ter manifestado interesse pelo marxismo e de ter se oposto ao estruturalismo, acabou por oferecer respostas a muitas das problematizações levantadas por grupos de abordagens tão díspares.

Emerson (2002) destaca que a geração de estudiosos que fez a redescoberta de $M$. Bakhtin muito contribui para o culto em torno da figura de Bakhtin, para a construção de uma mitologia desse pensador. Todavia, a consagração do nome de Bakhtin como um dos principais pensadores do século XX ocorre, de fato, com a difusão da sua produção teórica no mundo ocidental, a partir do final dos anos 1960, a chegada de sua fama e de seus textos na França, nos anos 1960, e nos Estados Unidos, nos anos 1970. Em 1968, a obra de Bakhtin sobre Rabelais chega à cena intelectual dos Estados Unidos, com a primeira tradução de Cultura Popular da ldade Média para o inglês. Também em 1968, essas obras foram publicadas em italiano. Em 1970, aparecem as primeiras traduções de textos de Bakhtin no mundo francófono, com a publicação da obra sobre a poética de Dostoiévski, intitulada Une poétique ruinée, em tradução de Isabelle Kolitchef, com prefácio de Julia Kristeva ${ }^{14}$. Também nesse ano, é apresentado ao público francês o livro sobre Rabelais.

A partir desse processo, a teoria bakhtiniana começa a se expandir para além da Rússia e emerge uma fortuna crítica ocidental dessa abordagem. Nesse contexto, a intelectualidade francesa exerceu importante papel na difusão do pensamento

\footnotetext{
${ }^{14}$ Júlia Kristeva (1941-) é uma semioticista e crítica literária búlgara, radicada na França. É um dos nomes de maior destaque na tradição estruturalista e pós-estruturalista francófona. KRISTEVA, Julia - Une poétique ruinée. In: La Poétique de Dostoievski. BAKHTINE, Mikhail. Trad. Isabelle Kolitcheff. Paris, Seuil, 1970. Na França, foram publicadas no mesmo ano, 1970, duas traduções diferentes de Problemas da Poética de Dostoiévski: esta prefaciada por J. Kristeva e outra traduzida por Guy Verret: BAKHTINE, Mikhail. La poétique de Dostoïevski. Trad.Guy Verret. Lausanne, Editions I"Age d"Homme, 1970.
} 
bakhthiniano no Ocidente. Julia Kristeva, antes do prefácio da edição de Problemas da Poética de Dostoiévski, já havia publicado, em 1967, na Revista Critique, o artigo "Bakhtine, le mot, le dialog et le roman"15, no qual essa autora apresenta Bakhtin como um continuador dos formalistas: "Bakhtin aborda problemas fundamentais que o estudo estrutural da narrativa enfrenta hoje e que tornam atual a leitura dos textos que ele esboçou há cerca de quarenta anos" (KRISTEVA, 2005, p. 66). Esses escritos de Kristeva são apontados por diversos estudiosos como uma espécie de marco inicial da recepção do pensamento bakhtiniano no Ocidente e ilustram bem a multiplicidade de leituras dessa teoria, de acordo com os diferentes contextos de recepção. O dialogismo bakhtiniano é, inclusive, o ponto de partida para Kristeva, a seu modo, desenvolver o conceito (tão difundido nos estudos linguísticos) de intertextualidade.

Essa leitura de Bakhtin por Kristeva - caracterizada por Sériot $(2015$, p.13) como um grande "catálogo de mal-entendidos" - é bem ilustrativa do processo que caracterizou a recepção dessa teoria na França: a tentativa de encaixá-la na atmosfera intelectual francesa dos anos 1960-1970. Assim como na Rússia, a publicação das obras do chamado Círculo de Bakhtin na Europa não ocorreu na ordem em que os textos foram elaborados. A obra MFL foi traduzida para o francês $m$ 1977, por Marina Yaguello. A publicação dessa edição francesa - com o nome de Mikhail Bakhtin como autor e, entre parênteses, o nome de V. Volóchinov - acompanhada de apresentação de Yagello e prefácio de Roman Jakobson assinalam um posicionamento em prol de Bakhtin acerca da polêmica autoria desse texto, publicado pela primeira vez em Leningrado, em 1929. Em 1978, foi publicada a tradução do livro Questões de Literatura e de Estética: a teoria do romance.

Nos anos posteriores, foram sendo publicadas outras obras bakhtinianas, a partir das edições russas, e o nome de Bakhtin ganhou cada vez mais um lugar de destaque no campo intelectual francófono. E é, sobretudo, a partir desse olhar francófono que o pensamento bakhtiniano é difundido no Brasil, em especial, a partir dos anos 1980.

\section{Análise Dialógica do Discurso: contexto de recepção do pensamento bakhtiniano no Brasil}

\footnotetext{
${ }^{15}$ Este ensaio, produzido a partir da leitura dos originais russos de Problemas da Poética de Dostoiévski (1963) e Cultura Popular na Idade Média e no Renascimento (1965), foi publicado, em uma coletânea de textos, na França, em 1969, intitulada Recherches pour une sémanalyse, traduzido, no Brasil, em 1974, sob o título Introdução à Semanálise. Na edição brasileira, esse artigo é denominado "A palavra, o diálogo e o romance".
}

Eutomia, Recife, 21(1): 120-143, Jul. 2018 
A publicação, no Brasil, da aguardada tradução da obra Marxismo e Filosofia da Linguagem: problemas fundamentais do método sociológico na ciência da linguagem, direta do russo, em 2017, é um marco para os estudos bakhtinianos brasileiros, tendo em vista que esta foi a primeira obra bakhtiniana traduzida no país, em 1979, e, por meio dela, conceitos como dialogismo, enunciação e interação entraram em cena no debate acadêmico nacional. Além disso, MFL, certamente uma das obras mais lidas do Círculo, ${ }^{16}$ é foco do polêmico debate em torno dos "textos disputados".

A primeira tradução brasileira de MFL, que está na 16a edição, foi feita por Michel Lahub e Yara Frateschi ${ }^{17}$, a partir da tradução francesa, de 1977, com cotejo à tradução norte-americana, de 1973. A obra traz prefácio de Roman Jakobson e apresentação de Marina Yaguello, dois autores que atribuem a autoria de MFL a M. Bakhtin, assim a edição utiliza o subterfúgio de registrar o nome de V.N.Volóchinov, entre parênteses, ao lado do de Mikhail Bakhtin. Vale ressaltar que uma diversidade de recursos tipográficos (barras, parênteses, dois pontos) foi utilizada em muitas traduções das obras "contestadas" mundo a fora, tendo em vista a polêmica questão da autoria.

Quase 30 anos separam as duas traduções e o fato de a primeira ter sido traduzida a partir da edição francesa e a segunda, a partir da edição russa de 1929 ilustra bem a mudança no contexto de recepção dessa obra. Conforme destaca Sériot (2015, p. 23), "as traduções envelhecem, é preciso atualizá-las regularmente, enquanto o original não se altera. Mas sua interpretação, sua recepção se modificam em função do tempo e do espaço". Assim, partindo de uma perspectiva da própria abordagem bakhtiniana, as traduções devem ser vistas como enunciados, "como elos na cadeia da comunicação discursiva", tal como debatido por Grillo (2014, p. 75).

A tradução de MFL a partir do francês é bem representativa da forte influência do olhar francófono sobre os estudos linguísticos no Brasil, ou seja, conforme já afirmamos, o pensamento bakhtiniano foi difundido no país, especialmente, a partir de lentes francófonas. Além disso, o contexto ditatorial vivido no Brasil, sobretudo nos anos 1960 e 1970, dificultava o acesso às obras oriundas diretamente da União Soviética e, muitas vezes, "um autor soviético só poderia ser lido em tradução ocidental" (SCHNAIDERMAN, 1983,

\footnotetext{
${ }^{16}$ Grillo (2014, p. 79) ressalta, entretanto, que "apesar de esse livro ser muito conhecido no Brasil, ele não teve a mesma notoriedade na União Soviética e na Rússia atual".

${ }^{17}$ (BAKHTIN/VOLOCHÍNOV, 2014).
} 
p.9). Nesse contexto, conforme discutido por Grillo (2014), também não se formaram muitos tradutores e as leituras das obras oriundas do mundo soviético eram realizadas, sobretudo, através do olhar ocidental, especialmente francês.

A tradução de MFL, direta do russo, foi realizada pela linguista eslavista, de naturalidade brasileira, Sheila Camargo Grillo, professora da área de Filologia e Língua Portuguesa da Universidade de São Paulo, e pela teórica da literatura, de naturalidade russa, Ekaterina Vólkova Américo, professora de Língua e Literatura Russa, da Universidade Federal Fluminense. Sheila Grillo tem uma consistente trajetória de pesquisa sobre Bakhtin e o Círculo, tendo realizado, inclusive, estudos de pós-doutorado no Instituto Górki da Literatura Mundial, em Moscou. A tradução de MFL é fruto de produtivas pesquisas que resultaram, anteriormente, na primeira tradução da obra - também alvo de disputa acerca da autoria - O método formal nos estudos literários. Introdução crítica de uma poética sociológica (MEDVIÉDEV, 2012), que não possuía, até então, nenhuma tradução para o português; e Questões de estilística no ensino no ensino da língua (BAKHTIN, 2013), também publicada pela primeira vez no Brasil.

A retradução de MFL foi feita a partir da primeira edição russa da obra, de 1929, com consultas à segunda edição, de 1930. Essa nova tradução é de grande relevância não apenas por ser realizada direto do russo, o que já permite uma aproximação maior com "os conceitos, o estilo e o contexto acadêmico da época" (GRILLO, 2014, p. 81), mas também por trazer um aprofundado ensaio, intitulado "Marxismo e Filosofia da Linguagem: uma resposta à ciência da linguagem do século XIX e início do século XX", de autoria de Sheila Grillo; além de um glossário de termos centrais em Marxismo e Filosofia da Linguagem e de um plano de trabalho do arquivo pessoal de V. N. Volóchinov, constante no Arquivo Estatal da Federação Russa. O plano faz parte de um dos relatórios apresentados por Volóchinov, na época de seus estudos doutorais no ILIAZV (Instituto de História Comparada das Literaturas e Línguas do Ocidente e do Oriente).

A respeito do glossário, Grillo (2014, p. 81) destaca que este poderá auxiliar "na manutenção de uma coerência na tradução dos conceitos, bem como na compreensão do núcleo conceitual de MFL pelo leitor brasileiro". O ensaio introdutório, segundo Grillo (2017), objetiva recuperar e compreender parte do contexto intelectual de produção da obra, ou, ainda "reconstruir parte da biblioteca virtual do autor", com intuito de possibilitar ao leitor brasileiro o acesso novos aspectos daquela conjuntura acadêmica. 
Esse empreendimento de aliar a tradução da obra direta do russo à produção de ensaios introdutórios (que também está presente na tradução de $O$ método formal nos estudos literários) e de um glossário de termos está ancorado na concepção de tradução como enunciado concreto, cuja compreensão não se restringe "ao domínio do léxico e da sintaxe das línguas de partida e de chegada", pois "envolve o conhecimento do contexto sócio-histórico e intelectual das obras traduzidas, sobretudo quando se trata de textos temporal e culturalmente distantes do leitor presumido" (GRILLO, 2014, p. 85).

Com relação à controversa questão da autoria de $M F L$, Sheila Grillo, em seu ensaio introdutório, afirma que não objetiva comprovar a autoria da obra e limita-se a declarar que manterá o nome do autor que figurava na primeira edição. Assim, na capa da tradução de 2017, uma diferença substancial à de 1979, aparece o nome de Valentin Volóchinov e entre parênteses a expressão Círculo de Bakhtin, que remete à defesa do profícuo diálogo entre os autores desse "coletivo de pensadores".

Sheila Grillo, todavia, não discute sobre esse posicionamento, apenas ressalta que não objetiva isolar as obras de V.N.Volóchinov das de seus contemporâneos, M. Bakhtin e P. Medviédev e remete à discussão que ela desenvolveu no prefácio de $O$ método formal nos estudos literários, no qual a tradutora apresenta diferentes posicionamentos acerca da autoria de $O$ método formal nos estudos literários: os que defendem autoria de Bakhtin; os que sustentam a autoria original de Medviédev; e os que advogam a coautoria. A autora ressalta, por fim, nesse prefácio, que "os dados disponíveis até o presente ${ }^{18}$ impedem a resolução da questão", portanto, no momento, a autora não considera possível, com relação a $O$ método formal nos estudos literários, assumir "uma posição unilateral sobre a autoria: a favor de Bakhtin, em defesa de P. Medviédev, ou mesmo de coautoria" (GRILLO, 2012, p. 36). Assim, a capa da edição de 0 método formal nos estudos literários traz, com bastante destaque, o nome do autor da obra, o signatário original, Pável Nikolaievitch Medviédev, e apenas na folha de rosto (opção editorial?), aparece, entre parênteses, em fonte bem menor, a expressão "Círculo de Bakhtin".

Com relação à obra MFL, podemos destacar que o intelectual russo, radicado nos Estados Unidos, Roman Jakobson, foi um dos responsáveis pela difusão do pensamento bakhtiniano no Ocidente, com a publicação pioneira da tradução de MFL, em inglês, no ano

\footnotetext{
${ }^{18}$ Vale lembrar que este texto foi publicado em 2012.
} 
de 1973. Essa primeira tradução, feita por L. Matejka e I.R. Titunik, apresenta como autor inconteste o nome de V. N. Volóchinov.

O debate acerca da autoria de MFL ganhou novo fôlego após a publicação, em 2010, na França, de uma edição bilíngue dessa obra, em russo-francês, com tradução de Patrick Sériot e Inna Tunowski-Ageeva. A publicação foi organizada por Patrick Sériot - professor de Linguística eslava na Universidade de Lausanne (Suíça), e especialista em história e epistemologia do discurso sobre a linguagem na Rússia e na União Soviética - que publicou, como prefácio dessa publicação, um aprofundado ensaio no qual discute a historicidade e epistemologia do pensamento de V.N.Volóchinov, nega a existência de um "Círculo de Bakhtin" e defende a autoria inconteste de Volóchinov da obra MFL. Esse prefácio foi traduzido para o português, em 2015, pelo linguista Marcos Bagno, e publicado sob o título Voloshinov e a filosofia da linguagem (SÉRIOT, 2015).

Reiterando que as traduções devem ser vistas como enunciados concretos, as diferentes perspectivas dos prefácios das duas traduções francesas de MFL assinalam a mudança no contexto de recepção da obra de Bakhtin e do chamado "Círculo". Sériot (2015) defende que a recepção de Bakhtin no mundo fancófono é mais uma doxa (que na filosofia refere-se a uma crença ingênua, subjetiva, que deve ser superada, pois carece de uma "episteme", de uma reflexão acerca da construção do conhecimento) do que uma opinião ou, menos ainda, um quadro conceitual. Nessa conjuntura, a publicação da nova edição de MFL na França, em 2010, é bastante significativa, tendo em vista que a edição francesa, publicada em 1977, é a primeira a atribuir a autoria a M. Bakhtin, apresentado o nome de Volóchinov entre parênteses. É a partir dessa edição francesa que é feita a primeira tradução de MFL, no Brasil, conforme já ressaltado.

Um ponto importante a se destacar a respeito da edição dessa primeira tradução brasileira é a presença do prefácio de Roman Jakobson e da apresentação de Marina Yaguello. Nesse texto, Jakobson (2014) aponta que MFL havia sido publicado, em 1929 e 1930, em Leningrado, entretanto, afirma, por meio da utilização de um sujeito indeterminado - sem muitos questionamentos ou provas verificáveis: "Acabou-se descobrindo que o livro em questão e várias outras obras publicadas no final dos anos vinte e começo dos anos trinta com o nome de Volochinov [...] foram, na verdade, escritos por Bakhtin" (JAKOBSON, 2014, p. 9). 
O texto de Yaguello é particularmente significativo, pois reproduz bem, naquele contexto de recepção do pensamento bakhtiniano, a mitologia em torno da figura de Bakhtin, que seria admirado e seguido por seus discípulos devotados que compunham um círculo em torno do mestre, o Círculo de Bakhtin. Segundo Yaguello, a devoção e o desejo de ajudar o mestre eram tamanhos que seus discípulos, quando o viram passando por uma situação material difícil, "animados pelo desejo de vir ajudar financeiramente a seu mestre e, ao mesmo tempo, divulgar suas ideias, ofereceram seus nomes a fim de tornar possível a publicação de suas primeiras obras" (YAGUELLO, 2014, p. 11). Essa autora aponta como alguns dos motivos para as supostas obras de Bakhtin terem sido publicadas sob outros nomes: o "gosto pela máscara e pelo desdobramento" e também a "profunda modéstia científica" de Bakhtin. É, em linhas gerais, nesses termos que essa linguista francesa, autoridade em sua área, contribui com a construção da narrativa mítica em torno da figura de Bakhtin e dos textos contestados, asseverando, naquela conjuntura, que "não há dúvidas quanto à paternidade de suas obras". Convém ressaltar que esse texto circula (e continua sendo publicado) na primeira tradução brasileira de MFL, e, por seu clima doxa, pode ser tomado como verdade trivial e reproduzido sem questionamentos pelo leitor mais desavisado.

Importante destacar que o pensamento bakhtiniano foi difundido no Brasil, inicialmente, no campo dos estudos literários, com destaque para a atuação pioneira do estudioso Boris Schnaiderman, que "publicou artigos e ensaios sobre Dostoiévski e Bakhtin, o qual se tornou referência nas suas aulas de literatura da graduação e pós-graduação" (CUNHA, 2012, p. 249). Pode-se destacar também o pioneirismo do crítico e ensaísta José Guilherme Merquior, na divulgação do pensamento bakhtiniano para os estudos literários e culturais no Brasil ${ }^{19}$.

Faraco (2014) destaca que a tradução de MFL abriu caminhos para estudos linguísticos a partir dessa abordagem, tendo em vista que revelou outra face daqueles pensadores russos, além da perspectiva literária: "a atenção à linguagem verbal, o que

\footnotetext{
${ }^{19}$ Tomando como referencial as obras de Bakhtin sobre Rabelais e Dostoiévski, Merquior produziu trabalhos como o ensaio, publicado em 1971, "Gênero e estilo das Memórias Póstumas de Brás Cubas", no qual o autor aplica o conceito bakhtiniano de carnavalização nessa obra do escritor Machado de Assis. Segundo Merquior, a fusão de humorismo filosófico e fantástico permite definir "Memórias Póstumas de Brás Cubas como um representante moderno do gênero cômico-fantástico" (MEROUIOR, 1972, p. 13). Esse texto, publicado originalmente, em Lisboa, ganhou o título de "O romance carnavalesco de Machado" e veio a público como ensaio introdutório a uma edição dessa obra machadiana, publicada em São Paulo, em 1975.
} 
atraiu o interesse de vários linguistas, seja por conter uma leitura crítica dos fundamentos de consagradas teorias linguísticas, seja pela proposta de uma linguística que o autor qualificava de sociológica" (FARACO, 2014, p. 11). Assim, foram entrando em cena, na recepção brasileira, outras obras do Círculo, em geral por tradução indireta.

A pós a publicação de Marxismo de Filosofia da Linguagem, em 1979, foram publicadas as seguintes obras: 1981 - Problemas da Poética de Dostoiévski (traduzido do russo por Paulo Bezerra); 1987 - A cultura popular na Idade Média e no Renascimento - o contexto de François Rabelais (traduzido por Yara Frateschi, a partir da tradução francesa de 1970; 1988 - Questões de literatura e de estética. A teoria do romance (Traduzido do russo por equipe coordenada pela professora Aurora Fornoni Bernardini); 1992 - Estética da Criação Verbal (Tradução feita por Maria Ermantina Galvão Pereira, a partir de edição francesa de 1980); 2001 - Freudismo: um esboço crítico (Traduzido do russo por Paulo Bezerra); 2003 Estética da Criação Verbal (Traduzido do russo por Paulo Bezerra); 2010 - Para uma Filosofia do Ato Responsável (Traduzido por Valdemir Miotello e Carlos Alberto Faraco, a partir da edição italiana de 2003); 2012 - O método formal nos estudos literários. Introdução crítica de uma poética sociológica (Traduzido do russo por Sheila Camargo Grillo e Ekaterina Vólkova Américo); 2013 - Questões de estilística no ensino da língua (Traduzido do russo por Sheila Camargo Grillo e Ekaterina Vólkova Américo); 2015 - Teoria do romance l: a estilística (Traduzido do russo por Paulo Bezerra); 2016 - Os gêneros do discurso (Traduzido do russo por Paulo Bezerra); 2017 - Notas sobre Literatura, cultura e ciências humanas (Traduzido do russo por Paulo Bezerra); 2017 - Marxismo e Filosofia da Linguagem: problemas fundamentais do método sociológico na ciência da linguagem (Traduzido do russo por Sheila Camargo Grillo e Ekaterina Vólkova Américo); 2018- Teoria do romance II: as formas do tempo e do cronotopo (Traduzido do russo por Paulo Bezerra).

Nessa síntese, parcial, da cronologia das publicações, no Brasil, das obras do Círculo, pode-se observar que, assim como em diversos países, as traduções não seguiram uma ordem cronológica em que os originais (ou as reedições) foram publicados na Rússia, o que assinala os desafios empreendidos pelos estudiosos dessa abordagem, que necessitam estar em constante reavaliação e aprofundamento das leituras da produção teórica desse coletivo de pensadores.

Vale ressaltar que também circulam, entre os estudiosos brasileiros, traduções para fins didáticos, como a do artigo de V. N. Volóchinov "Discurso na vida e discurso na arte: 
sobre poética sociológica", realizada por Carlos Alberto Faraco e Cristovão Tezza, a partir da tradução inglesa de 1976; e o artigo também desse autor, "Estrutura do enunciado", traduzido por Ana Vaz, a partir da tradução francesa de 1981.

Em 2011, foi publicada, pela Pedro e João Editores, uma tradução que reúne a terceira parte de Marxismo e Filosofia da Linguagem e o artigo "Discurso na vida e discurso na arte: sobre poética sociológica" (sob o título "A palavra na vida e na poesia: introdução ao problema da poética sociológica"), a partir de tradução italiana de 2010. Entre as publicações dessa editora, merece destaque o livro "A construção da enunciação e outros ensaios", de 2013, que reúne, a partir de tradução italiana, coletânea de artigos produzidos por V. N. Volóchinov. Além de trazer artigos de Volóchinov, inéditos no Brasil, a obra apresenta um ensaio introdutório de João W. Geraldi e materiais de arquivo da produção da obra Marxismo e Filosofia da Linguagem.

O livro Teoria do romance I: a estilística, publicado em 2015, traz uma versão original do artigo "O discurso no romance", sem os cortes e adaptações que haviam sido feitos na edição original a partir da qual foi publicado esse texto no Brasil, na coletânea Questões de literatura e de estética (1988). Essa nova tradução é o primeiro número da obra Teoria do Romance, que a Editora 34 objetiva publicar em três volumes. Esse texto foi publicado na Rússia, em 2012, e faz parte das Obras Reunidas, de M. Bakhtin, organizada pelos herdeiros dos seus direitos autorais, S. Bocharov e V. Kozinov. Em 2018, foi publicado o segundo volume da coleção, com o título Teoria do romance II: as formas do tempo e do cronotopo.

Em 2016, foi publicado, pela mesma editora, a obra Os gêneros do discurso, com organização, tradução e posfácio de Paulo Bezerra. Esta obra é uma retradução de "Os gêneros do discurso" e "O problema do texto na linguística e nas outras ciências humanas: uma experiência de análise filosófica", já publicados em Estética da Criação Verbal. Apresenta, ainda os textos inéditos "Diálogo I. A questão do discurso dialógico" e "Diálogo II". Os textos reunidos neste livro foram traduzidos a partir do tomo 5 das Obras Reunidas de M. Bakhtin, publicado em Moscou, em 1997. Já o livro Notas sobre literatura, cultura e ciências humanas, publicado em 2017, também reúne textos que estão nas Obras Reunidas, escritos nos anos 1970, anteriormente publicados na coletânea Estética da Criação Verbal.

Assim, pode-se pontuar as mudanças no contexto de recepção, assinaladas pela profusão de traduções a partir do russo nos últimos anos, que também é índice de uma 
tendência de voltar-se para as fontes do pensamento do Círculo e para o aprofundamento de seu universo conceitual.

\section{Considerações finais}

Pode destacar, por fim, que, a partir do esforço contínuo dos pesquisadores brasileiros, há hoje uma diversidade de abordagens, em especial nos estudos da linguagem, inspiradas no pensamento bakhtiniano. Cunha (2012) destaca que a recepção dos autores russos no Brasil, nos últimos 40 anos, tem sido bastante produtiva. Essa autora ressalta que, nos anos 1960, o pensamento bakhtiniano surgiu como uma referência nos estudos de literatura. Já nos anos 1980, a tradução brasileira de Marxismo e Filosofia da Linguagem influenciou os estudos linguísticos na crítica ao estruturalismo hegemônico. Nos anos 1990, o pensamento bakhtiniano ganhou destaque nos estudos da língua, inclusive, nos documentos oficiais como os Parâmetros Curriculares Nacionais (PCNs), que adotam as concepções de linguagem e gêneros de discurso a partir da teoria bakhtiniana. Cunha (2012) enfatiza, ainda, que, nos anos 2000, multiplicaram-se os estudos que fazem uso de conceitos dos autores russos e emergiu uma série de pesquisas que têm como norte as propostas teóricas de Bakhtin e do Círculo. Paula (2013), por sua vez, destaca que há uma diversidade de leituras dos escritos desses teóricos, nos vários países em que eles foram traduzidos, assim, é possível, segundo essa autora, pensarmos na leitura que o Brasil faz das obras do Círculo de Bakhtin como um tipo de Análise do Discurso, a qual Brait $(2006,2010)$ denomina Análise Dialógica do Discurso. A Análise Dialógica do Discurso "origina-se sem a historicidade consagrada à Análise de Discurso Francesa, por exemplo, instaura-se a partir das obras escritas por Bakhtin e seu Círculo e, mais especificamente, pela maneira como essas obras foram sendo conhecidas, lidas e interpretadas nas últimas décadas (BRAIT, 2008, p. 117).

Neste sentido, conforme destacado por Brait (2012, p.12), a produtividade e a história do pensamento bakhtiniano, "no ponto em que chegou, não tem possibilidade de ser apagada ou interrompida. A concepção bakhtiniana de linguagem está aí, dada pelo conjunto das obras e suas traduções". Tendo em vista o lugar hoje ocupado pela teoria bakhtiniana nos estudos da linguagem e o profícuo debate acerca do legado dessa abordagem, cabe, portanto, a nós, pesquisadores, traçarmos os caminhos a serem 
percorridos por essa perspectiva teórica, sem desconsiderar a necessidade de uma postura reflexiva e crítica sobre os processos de consagração e legitimação desse arcabouço teóricometodológico.

\section{Referências bibliográficas}

BAKHTIN, M. Estética da criação verbal. Trad. Paulo Bezerra. 6. ed. São Paulo, Martins Fontes, 2011.

. Questões de estilística no ensino da língua. Tradução do russo de Sheila Grillo e Ekaterina Vólkova Américo. São Paulo: Editora 34, 2013.

. Teoria do romance I: a estilística. Tradução do russo, notas e glossário de Paulo Bezerra. São Paulo: Editora 34, 2015.

. Os gêneros do discurso. Organização, tradução, posfácio, notas e glossário de Paulo Bezerra; notas da edição russa de Serguei Bocharov. São Paulo, Editora 34, 2016.

. Notas sobre literatura, cultura e ciências humanas. Organização, tradução, posfácio e notas de Paulo Bezerra; notas da edição russa de Serguei Bocharov. São Paulo, Editora 34, 2017.

. Teoria do romance II: as formas do tempo e do cronotopo. Tradução do russo, posfácio e notas de Paulo Bezerra. São Paulo: Editora 34, 2018.

BAKHTIN, M. (V.N. VOLOCHÍNOV). Marxismo e Filosofia da Linguagem: Problemas fundamentais do método sociológico na Ciência da Linguagem. Trad. Michel Lahub e Yara Frateschi Vieira. 16. ed. São Paulo: Hucitec, 2014.

BRAIT, B. "Uma perspectiva dialógica de teoria, método e análise". In: Gragoatá.

Publicação de Pós-Graduação em Letras da Universidade Federal Fluminense. Niterói, n. 20, p. 47-62. $1^{\circ}$ sem, 2006.

. Memória, linguagens, construção de sentidos. In: LARA, G. M. P.; MACHADO, I. L.; EMEDIATO, W. (org.) Análises do discurso hoje. Vol. 2, Rio de Janeiro, Nova Fronteira, 2008, p. 115-132.

. CAMPOS, M. I. B. Da Rússia czarista à web. In: BRAIT, B. (Org.). Bakhtin e o Círculo. São Paulo: Contexto, 2009, p. 15-30.

. Análise e teoria do discurso. In: Bakhtin: outros conceitos-chave. São Paulo:

Contexto, 2010, p. 9-31. 
Importância e necessidade da obra O Método Formal nos Estudos Literários: introdução a uma poética sociológica. Apresentação. In: O método formal nos estudos literários: introdução crítica a uma poética sociológica. Tradução de Ekaterina Vólkova Américo e Sheila Camargo Grillo. São Paulo: Contexto, 2012.

BEZERRA, P. Prefácio. In: Problemas da poética de Dostoiévski. Trad. Paulo Bezerra. 4 ed. ampliada. Rio de Janeiro: Forense Universitária, 2013.

BRANDIST, C. The Bakhtin Circle. Philosophy, Culture And Politics. London/Sterling, Virginia: Pluto Press, 2002.

. Repensando o Círculo de Bakhtin: novas perspectivas na história intelectual. São Paulo, Contexto, 2012. Trad. Rosemary Schettini e Nathalia S. Polachini.

BRONCKART, J.P.; BOTA, C. Bakhtin desmascarado. História de um mentiroso, de uma fraude, de um delírio coletivo. São Paulo: Parábola Editorial, 2012.

CLARK, K.; HOLQUIST, M. Mikhail Bakhtin. Cambridge, Massachussets:

Harvard University Press, 2004.

CUNHA, D. A, C. "Dialogismo e pontos de vista: um estudo da charge". In: Eutomia: Revista de Literatura e Linguística. Edição 9, Ano V, jul. 2012.

EMERSON, C. Os cem primeiros anos de Mikhail Bakhtin. Tradução Pedro Jorgensen Jr. Rio de Janeiro: DIFEL, 2003.

FARACO, C. A. Linguagem \& Diálogo: as ideias linguísticas do Círculo de Bakhtin. Curitiba/PR: Criar Edições, 2009.

. Introdução. In: BRAIT, B. e MAGALHÃES, A. S. Dialogismo - teoria e(m) prática. São Paulo: Terracota, 2014 .

GRILLO, S. V. de C. "As traduções brasileiras de Bakhtin, Medviédev e Volóchinov. In: BRAIT, B. e MAGALHÃES, A. S. Dialogismo - teoria e(m) prática. São Paulo: Terracota, 2014, p.75-90.

A obra em contexto: tradução, história e autoria. Prefácio. In: MEDVIÉDEV, Pável Nikoláievitch. $O$ método formal nos estudos literários: introdução crítica a uma poética sociológica. Tradução de Ekaterina Vólkova Américo e Sheila Camargo Grillo. São Paulo: Contexto, 2012.

. "Marxismo e Filosofia da Linguagem: uma resposta à ciência da linguagem do século XIX e início do século XX". Ensaio Introdutório. In: VOLÓCHINOV. V.N. Marxismo e filosofia da linguagem: problemas fundamentais do método sociológico na ciência da linguagem. Tradução de Sheila Grillo e Ekaterina Vólkova Américo. São Paulo: editora 34, 2017, p. 7-79.

GRILLO, S.V.C.; AMERICO, E. V. Valentín Nikoláievitch Volóchinov: detalhes da vida e da obra encontrados em arquivos. Alfa, rev. linguíst. (São José Rio Preto), São Paulo, v. 61, n. 
2, p. 255-281, Aug. 2017. Disponível em: < http://dx.doi.org/10.1590/1981-5794-1709-1>. Acesso em 23. marc. 2018.

JAKOBSON, R. Prefácio. In: BAKHTIN, M. (V.N. VOLOCHÍNOV). Marxismo e Filosofia da Linguagem: Problemas fundamentais do método sociológico na Ciência da Linguagem. Trad. Michel Lahub e Yara Frateschi Vieira. 5. ed. São Paulo: Hucitec, 2014. KRISTEVA, J. Introdução à semanálise. 2. Ed. São Paulo: Perspectiva, 2005.

MEDVIÉDEV, P.N. O método formal nos estudos literários: introdução crítica a uma poética sociológica. Tradução de Ekaterina Vólkova Américo e Sheila Camargo Grillo. São Paulo: Contexto, 2012.

MEDVIÉDEV, I.P.; MEDVIÉDEVA, D. A.; SHEPHERD, D. "A polifonia do Círculo". Bakhtiniana. Revista de Estudos do Discurso, [S.I.], v. 11, n. 1, p. Eng. 89-128/ Port. 99-144, nov. 2015. ISSN 2176-4573. Disponível em:

<https://revistas.pucsp.br/index.php/bakhtiniana/article/view/24397/18211>. Acesso em: 23 jan. 2018.

MEDVIÉDEV, I.P.; MEDVIÉDEVA, D. A. "O Círculo de M. M. Bakhtin: sobre a fundamentação de um fenômeno". Bakhtiniana. Revista de Estudos do Discurso, [S.I.], v. 9, p. Port. 26-46/ Eng. 28-48, jun. 2014. ISSN 2176-4573. Disponível em:

https://revistas.pucsp.br/index.php/bakhtiniana/article/view/11535 > Acesso em: 23 abr. 2017.

MERQUIOR, J. G. O romance carnavalesco de Machado. In: ASSIS, M. de. Memórias póstumas de Brás Cubas. São Paulo: Ática, 1975.

. Gênero e estilo das Memórias Póstumas de Brás Cubas. Colóquio/Letras n.8, julho, Lisboa, 1972. p. 12-20. Disponível em: < http://coloquio.gulbenkian.pt/bib/sirius.exe/issueContentDisplay? $n=8 \& p=12 \& 0=p>$ Acesso em 19. fev.2018.

MORSON, G.S.; EMERSON, C. Mikhail Bakhtin: criação de uma prosaística. Tradução de Antonio de Pádua Danesi. São Paulo: Edusp, 2008.

PAULA, L.de. "Círculo de Bakhtin: uma Análise Dialógica de Discurso". Revista de Estudos da Linguagem, v. 21, n. 1, p. 239-258, 2013.

PAULA, L.de; STAFUZZA, G. (org.). Círculo de Bakhtin: teoria inclassificável. Campinas: Mercado de Letras, 2010. (Volume 1. Série Bakhtin - Inclassificável).

Círculo de Bakhtin: diálogos (in)possíveis. Campinas: Mercado de Letras, 2011. (Volume 2. Série Bakhtin - Inclassificável).

Círculo de Bakhtin: pensamento interacional. Campinas: Mercado de Letras, 2013. (Volume 3. Série Bakhtin - Inclassificável) 
SCHNAIDERMAN, B. Turbilhão e semente. Ensaios sobre Dostoiévski e Bakhtin. São Paulo: Duas Cidades, 1983.

SÉRIOT, P. Voloshinov e a filosofia da linguagem. Trad. de Marcos Bagno. São Paulo: Parábola Editorial, 2015.

VOLÓCHINOV. V.N. Marxismo e filosofia da linguagem: problemas fundamentais do método sociológico na ciência da linguagem. Tradução de Sheila Grillo e Ekaterina Vólkova Américo. São Paulo: editora 34, 2017.

A construção da enunciação e outros ensaios. Organização, tradução e notas de João Wanderley Geraldi. São Carlos, SP: Pedro \& João Editores, 2013.

YAGUELLO. M. Introdução. In: BAKHTIN, M. (V.N. VOLOCHÍNOV). Marxismo e Filosofia da Linguagem: Problemas fundamentais do método sociológico na Ciência da Linguagem. Trad. Michel Lahub e Yara Frateschi Vieira. 5. ed. São Paulo: Hucitec, 2014.

\footnotetext{
' Doutoranda do Programa de Pós-Graduação em Linguística Aplicada da Universidade Estadual do Ceará (PosLA/UECE). Mestre em Linguística Aplicada (PosLA/ UECE). Especialista em Ensino de Língua Portuguesa (UECE). Graduada em Letras - Português/ Literatura (UECE) e em Comunicação Social/ Jornalismo - UFC (Universidade Federal do Ceará).

E-mail: beneditasipriano@gmail.com

ii Graduado em Letras pela Universidade Federal do Ceará (1994), mestre em Linguística pela Universidade Federal do Ceará (1998), doutor em Linguística pela Universidade Federal do Ceará (2006) e pós-doutor em Linguística pela Universidade Federal do Ceará (2016). Atualmente é Adjunto IV da Universidade Estadual do Ceará, coordenador do Curso de Especialização em Ensino de Língua Portuguesa da Universidade Estadual do Ceará e vice-coordenador do Programa de Pós-Graduação em Linguística Aplicada da Universidade Estadual do Ceará (PosLA/UECE). Tem experiência na área de Letras, com ênfase em Língua Portuguesa, e desenvolve pesquisas centradas nos estudos bakhtinianos do discurso.

E-mail: jbcgon@ig.com.br
} 